\title{
Synthesis, structural elucidation and carbon dioxide adsorption on Zn (II) hexacyanoferrate (II) Prussian blue analogue
}

R. Roque-Malherbe ${ }^{* a}$, F. Lugo ${ }^{a}$, and R. Polanco

School of Science, University of Turabo, PO Box 3030, Gurabo, PR, 00778-3030, USA.

* Corresponding author: Prof. R. Roque-Malherbe, email: rroquemalh@aol.com; Phone: 1-787930-2319.

a. Present address: PO Box 2017, PMB 405, Las Piedras, PR 00771, USA 


\section{ABSTRACT}

In the course of the last years hexacyanoferrates have been widely studied; even though, the adsorption properties of $\mathrm{Zn}$ (II) hexacyanoferrate(II) (labeled here $\mathrm{Zn}$-HII) has not been thoroughly considered. In addition, soft porous crystals, i.e., adsorbents that display structural flexibility have been, as well, extensively studied, however this property has not been reported for $\mathrm{Zn}$ (II) hexacyanoferrate(II). In this regard, the key questions addressed here were the synthesis and structural characterization of Zn-HII together with the investigation of their low (up to 1 Bar) and high pressure (up to 30 Bar) adsorption properties, to found if these materials show structural flexibility. Then, to attain the anticipated goals, structural characterizations were made with: X-ray diffraction (XRD), scanning electron microscopy (SEM), energy dispersive Xray analysis (EDAX), diffuse reflectance infrared Fourier transform spectrometry (DRIFTS) and thermo-gravimetric analysis (TGA), simultaneously, with the investigation of the adsorption of carbon dioxide. As a result of the research process we concluded that the Zn-HII displayed $F m \overline{3} m$ space group framework. Besides, the carbon dioxide adsorption investigation demonstrated the presence of the framework expansion effect together with an extremely high adsorption heat, properties that could be useful for the use of $\mathrm{Zn}$ (II) hexacyanoferrate(II) as an excellent adsorbent.

Keywords: carbon dioxide, adsorption, hexacyanoferrate, adsorption heat, gas storage. 


\section{INTRODUCTION}

Transition metal cyanides display structures assembled with transition metals, attached through the linear cyanide [1-10]. These compounds due to their magnetic [4], adsorption [5-8] and other properties are an important class of materials. Specially, metal hexacyanometalates are a notable group of transition metal cyanides. The basic component of the structure of hexacyanometallates, also known as PBAs is the linear, $-M^{-}-C \equiv N-M-N \equiv C-M^{\cdot}-$ chain [6]. As a result, their structural framework is associated to the perovskite structure; even though, the metal centers are linked by the cyanide bridges instead of oxide ions [9]. Subsequently, since the basic structural element is straight, hence hexacyanometallates should crystallize in the cubic system, more precisely, in the $F m \overline{3} m$ space group and in less extent in the $\operatorname{Pm} \overline{3} m$ [4]. Although, for some metals, specific distortions produce the crystallization of hexacyanometallates in the tetrahedral, $I 4 m m, I \overline{4} m 2[7]$ and in less extent in other space groups [10].

It is necessary to remark that the presence of $\left[M^{\prime}(X)(C N)_{6}\right]^{\mu-}$ vacancies produce a channel network, shaped by cavities, where the exchangeable metal, $A$, is located on these voids to generate charge balance [5,6]; acting, also, as charge centers capable to produce electrostatic interactions with the adsorbed molecules. Specifically, in the case of carbon dioxide; given that this molecule has a quadrupole moment it strongly interacts with the electric field gradients within the cavity [11].

In the specific case of hexacyanoferrates the generalized formula can be expressed as follows: $A_{a} M_{\beta}\left[\mathrm{Fe}\left(\mathrm{CN}_{6}\right)\right]_{\delta} \cdot n \mathrm{H}_{2} \mathrm{O}$, in which, $\mathrm{A}$, is normally an alkaline metal, $M$, is in general a transition metal, $\mathrm{Fe}=\mathrm{Fe}(\mathrm{X})), \mathrm{X}=\mathrm{II}$ or III, and $\mathrm{nH}_{2} \mathrm{O}$ are coordinated and loosely bound water molecules filling the $\left[\mathrm{Fe}(\mathrm{X})(\mathrm{CN})_{6}\right]^{\mu-}$ vacancies, that forms the microporous framework $[7,12]$. 
During the last years the investigation of hexacyanometallates became an expanding research field; particularly, zeolite-like hexacyanometallates have received particular attention as porous solids for the adsorption of small molecules; as a result of their microporous framework [11]. Besides, a group of porous materials known as soft porous crystals (SPC) have been investigated on account of their structural flexibility [13-15]. These materials undergo different framework transformations produced by external stimuli, such as, mechanical stress, adsorption or temperature [13]. In the case where the outside stimulus is the interaction of the guest molecules with the framework, the structural transformations are manifested by the atypical adsorptiondesorption isotherm patterns observed [14]. Particularly, gate opening effects are characterized by a big hysteresis loop between the adsorption and desorption branch of the isotherm [15].

Carbon dioxide is a good probe molecule to test framework transformations during adsorption, owing to the relatively high value of their quadrupolar moment ( $\left.Q_{\mathrm{CO}_{2}}=-4.3 \times 10^{-42} \mathrm{C} \cdot \mathrm{m}^{2}[16]\right)$; since, when it is adsorbed at low coverage become subjected to the dispersion, $\phi_{D}$, repulsion, $\phi_{R}$, and field gradient quadrupole, $\phi_{E Q}$ interaction energies [3]; where, $\phi_{E Q}=Q_{\mathrm{CO}_{2}} / 2(\partial E / \partial z)$; in which $(\partial E / \partial z)$, is the electric field gradient within the adsorption space [11].

PBAs are good adsorbents of small molecules [17-23]; hence, the main questions investigated here were, the synthesis and structural characterization of a $\mathrm{Zn}(\mathrm{II})$ hexacyanoferrate(II) (labeled Zn-HII); together, with the investigation of carbon dioxide adsorption in the low pressure (up to $1 \mathrm{Bar}$ ) and high pressure (up to $30 \mathrm{Bar}$ ) ranges, to investigate the structural transformations induced by adsorption in the framework of the tested Prussian blue analogue.

To perform the corresponding experimental work the structural characterizations of the $\mathrm{Zn}-\mathrm{HII}$ was done, by using X-ray diffraction (XRD); besides, a morphological study of the synthesized hexacyanoferrate was made with a scanning electron microscope (SEM); furthermore, the 
elemental composition was measured by means of the energy dispersive X-ray analysis (EDAX) facility included in the SEM; thereafter, the state of water in the $\mathrm{Zn}$-HII material was investigated using thermo-gravimetric analysis (TGA), finally low and high pressure carbon dioxide adsorption was studied to closely examine the adsorption space of the produced hexacyanoferrate.

\section{EXPERIMENTAL SECTION}

\subsection{Synthesis}

The consumable chemicals were analytical grade. Water was bi-distilled. To start with, the synthesis of the $\mathrm{Zn}(\mathrm{II})$ hexacyanoferrate(II) material was performed as follows: were mixed 0.025 moles of solid potassium hexacyanoferrate(II) and solutions containing 0.025 moles of $\mathrm{Zn}\left(\mathrm{NO}_{3}\right)_{2}$ for $250 \mathrm{~mL}$ of water, at $70{ }^{\circ} \mathrm{C}$, under constant stirring. Later, the formed precipitate was filtered, washed with distilled water and dried at $343 \mathrm{~K}$ for $24 \mathrm{~h}$ to get the sample labelled Zn-HII.

\subsection{Methods}

Firstly, the XRD profiles were gathered with a Bruker D8 Advance system in Bragg-Brentano vertical goniometer configuration. The $2 \theta$ angular measurements were made by applying steps of 0.01 degree. The $\mathrm{X}$-ray radiation source was a ceramic $\mathrm{Cu}$ anode tube. Variable Soller slits were included and a $\mathrm{Ni}$ filter was placed, prior to the detector. Additionally, a LynxEye ${ }^{\mathrm{TM}}$ onedimensional detector was used to produce large counting that resulted to high quality XRD profiles that can be accurately resolved by least square methods [17]. To confirm the assigned structure of the synthesized materials, the gathered XRD patterns were refined with the Pawley method. The computer program used to perform the Pawley refining processes was the Bruker 
DIFFRACplus TOPAS ${ }^{\mathrm{TM}}$ software package. The emission profile used in the refining processes was shaped by two Lorentzians displaying the following parameters, $A_{l}=0.654, \lambda=1.5406 \AA$, $\Delta \lambda=0.5 \mathrm{~m} \AA$ and $A_{2}=0.346, \lambda=1.5545 \AA, \Delta \lambda=0.63 \mathrm{~m} \AA[23]$.

Secondly, the SEM study was carried out with a JEOL JSM-6360, whose electron beam acceleration voltage was $20 \mathrm{kV}$. The tested sample grains were homogeneously placed on a carbon tape and different spots were examined. Using these specifications different images of the studied materials were obtained. As well, the elemental chemical analysis of the as-synthesized and washed samples, were performed using an EDAX spectrometer coupled into the microscope. To improve the accuracy, five elemental compositions in different spots were measured, then calculated the average composition.

Afterwards, diffuse reflectance infrared Fourier transform spectra were gathered using a Thermo Scientific Nicolet iS10 FTIR spectrometer. The data were collected at a resolution of $4 \mathrm{~cm}^{-1}$ employing 100 scans per sample. The hydrated samples spectra were obtained at room temperature under $\mathrm{N}_{2}$ flow (Praxair, $99.99 \%$ ) at a rate of $50 \mathrm{cc} / \mathrm{min}$. To get the spectra of the dehydrated samples, it were heated, to $100{ }^{\circ} \mathrm{C}$, under a flow of $\mathrm{N}_{2}$ (Praxair, $99.99 \%$ ) at a rate of $50 \mathrm{cc} / \mathrm{min}$ for 2 hours. The spectra of the dehydrated materials were then obtained at room temperature, under $\mathrm{N}_{2}$ (Praxair, $99.99 \%$ ) flow at a rate of $50 \mathrm{cc} / \mathrm{min}$. In addition, DRIFTS spectra of carbon dioxide adsorbed in the PBA framework were obtained using as background the dehydrated sample at room temperature. After that, $\mathrm{CO}_{2}$ (Praxair, $99.99 \%$ ) flow at a rate of $50 \mathrm{cc} / \mathrm{min}$ for three minutes was passed through the dehydrated samples; then, the sample was purged under $\mathrm{N}_{2}$ (Praxair, $99.99 \%$ ) flow at a rate of $50 \mathrm{cc} / \mathrm{min}$ for one minute. The spectrum of the carbon dioxide molecule adsorbed on the PBA microporous framework, were then obtained at room temperature under $\mathrm{N}_{2}$ flow. 
Lastly, carbon dioxide (Praxair, $99.99 \%$ ) adsorption was investigated at $273 \mathrm{~K}$ and $300 \mathrm{~K}$ in the low pressure (LP) range (pressure up to $1 \mathrm{bar}$ ) on samples degassed at $373 \mathrm{~K}$ for four hours in high vacuum ( $10^{-6}$ Torr) in a Quantachrome AS-1 automatic sorption analyzer. To measure the carbon dioxide (Praxair, $99.99 \%$ ) adsorption at temperatures of $273 \mathrm{~K}, 300 \mathrm{~K}$ and $318 \mathrm{~K}$ on samples degassed at $373 \mathrm{~K}$ for four hours in high vacuum $\left(10^{-6} \mathrm{Torr}\right)$ in the high pressure range (pressure up to 30 bar) a Quantachrome iSorbHP-100 was used. The backfilling process was performed using helium (Praxair, $99.99 \%$ ) in both cases.

Finally, the curve fitting processes were performed with the analysis and peak separation software PeakFit ${ }^{\circledR}$ (Seasolve Software Inc., Framingham, Massachusetts) based on a least square procedure using the method developed by Levenberg and Marquardt, making possible the calculation of the best fitting parameters.

\section{RESULTS AND DISCUSSION}

\subsection{Synthesis.}

For the synthesis of the M(II) hexacyanoferrate (II) several methods have been reported during the last years; namely, precipitation, growth in a gel, growth on a solid alkali-metal ferrocyanide and others [17-22]. Here we applied a precipitation method to produce the $\mathrm{Zn}(\mathrm{II})$ hexacyanoferrate (II). In this regard, were mixed solid potassium hexacyanoferrate(II) and solutions containing of $\mathrm{Zn}\left(\mathrm{NO}_{3}\right)_{2}$ under constant stirring, to get after: precipitation, filtration, washing with distilled water and drying the sample labelled Zn-HII. 


\subsection{Structural elucidation.}

The average elemental composition, $\mathrm{C}_{\mathrm{X}}$, in molar per-cent for the synthesized hexacyaanoferrate (Zn-HII) is $\mathrm{C}_{\mathrm{K}}=0.4(2) ; \mathrm{C}_{\mathrm{Fe}}=1.0(5) ; \mathrm{C}_{\mathrm{Zn}}=2.1$; giving that, the generalized formula can be expressed as follows: $A_{\alpha} M_{\beta}\left[\mathrm{Fe}\left(\mathrm{CN}_{6}\right)\right]_{\delta} \cdot n \mathrm{H}_{2} \mathrm{O}$, in which, $\mathrm{A}$, an alkaline metal, $M$, a transition metal, such as, $\mathrm{Fe}=\mathrm{Fe}(\mathrm{X})), \mathrm{X}=\mathrm{II}$ or III, and $\mathrm{nH}_{2} \mathrm{O}$ are coordinated and loosely bound water molecules filling the $\left[\mathrm{Fe}(\mathrm{X})(\mathrm{CN})_{6}\right]^{\mu-}$ vacancies that forms the microporous framework, occupying one-third of the these sites to maintain charge neutrality in the crystal [5].

In Fig. 1a is exhibited the collected XRD profile corresponding to the as-synthesized Zn-HII sample fitted with the Pawley method, assuming the $F m \overline{3} m$ space group. The fitting process allowed us to refine the cell parameter obtaining the results exhibited in Table 1. Next, in Fig. 1b is shown the SEM image corresponding to the produced Zn-HII material, where are observed cubic shape crystals.

Then, in Fig. 2 are shown the DRIFTS spectrum of the as-synthesized sample in the range between 1500 to $2500 \mathrm{~cm}^{-1}$ (Fig. 2a); together with the spectra of the hydrated and dehydrated $\mathrm{Zn}$-HII in the range between 2500 to $4000 \mathrm{~cm}^{-1}$ (Fig. 2b). The main IR active vibrations observed in the $1500-2500 \mathrm{~cm}^{-1}$ range are the absorption bands corresponding to the $\mathrm{OH}$ bending and the $\mathrm{CN}$ stretching modes (Fig. 2a). Specifically, the peak located at $1610 \mathrm{~cm}^{-1}$ is related to the $\mathrm{OH}$ bending and the peaks at $2103 \mathrm{~cm}^{-1}$ and $2180 \mathrm{~cm}^{-1}$ were associated to the $\mathrm{CN}$ stretching vibration, $F e(I I)-C \equiv N-Z n(I I)$ and this stretching vibration when this group was surrounded by $\mathrm{K}^{+}$, respectively [25]. Likewise, the bands present in the $2900-3900 \mathrm{~cm}^{-1}$ range (Fig. 2b) were related to the hydroxyl functionalities; where, $\mathrm{H}$-bonded, $\mathrm{OH}$ groups, exhibits a broad absorption band 2800-3400 $\mathrm{cm}^{-1}$, resulting from the superposition of hydrogen bonded interacting $\mathrm{OH}$ 
groups (Fig. 2b), meanwhile free $\mathrm{OH}$ groups which are not H-bonded exhibited an absorption band at ca., $3400-3600 \mathrm{~cm}^{-1}$.

Now, using the gathered characterization information (Figs. 1 and 2), in conjunction with the reported crystallographic information for the Zn-HII (Table 1) and the atomic positions, Wyckoff sites and occupancy factors reported in the International Tables for Crystallography for the $F m \overline{3} m$ space group [24]; was generated with the software PowderCell-2.4, the unit cell representation (Fig.3a) and the corresponding simulated XRD profile (Fig. 3b) corresponding to the synthesized PBA. It is now necessary to state that the simulated (Fig. 3b) and experimental XRD (Fig. 1a) profiles evidenced an absolute similarity. Consequently, the cubic framework reported in Fig. 3a correspond to the unit cell of the synthesized PBA in the dehydrated state.

Finally, to close the present section we can conclude that the synthesized Prussian blue analogue, i.e., the $\mathrm{Zn}$-HII material, as far as we know, is a different polymorph; given that, in literature are reported $\mathrm{Zn}$ (II)-hexacyanoferrates (II) that crystallizes in the, hexagonal, trigonal and cubic systems $[8,18]$; however, the cubic ones exhibited cell parameters different [20-22] to those reported here for the synthesized Zn-HII-PBA.

\subsection{Carbon dioxide adsorption on the Zn-HII.}

To collect the DRIFTS spectrum of adsorbed carbon dioxide, the produced PBA was heated at $373 \mathrm{~K}$ under a flow of $\mathrm{N}_{2}$ at $50 \mathrm{ml} / \mathrm{min}$ rate for 2 hours inside the high temperature DRIFTS cell, to dehydrate the tested material. After that the spectrum of adsorbed $\mathrm{CO}_{2}$ was obtained, as was previously explained. Afterwards, the infrared peak resolution, was made, using the PeakFit ${ }^{\circledR}$ software, yielding two peaks, i.e., a large peak located at $2346 \mathrm{~cm}^{-1}$ and a smaller one placed at $2332 \mathrm{~cm}^{-1}$ (Fig. 4). 
It is well known that the free carbon dioxide molecule belongs to the $D_{\infty \mathrm{ch}}$ point group symmetry, showing four fundamental vibration modes; namely, the symmetric stretching, $v_{1}\left(1338 \mathrm{~cm}^{-1}\right)$ the doubly degenerate bending vibration, $v_{2 a}$ and $v_{2 b}\left(667 \mathrm{~cm}^{-1}\right)$, and the asymmetric stretching vibration $v_{3}\left(2349 \mathrm{~cm}^{-1}\right)$ [26-31]. The, $v_{2}$ and $v_{3}$, modes are infrared active, whereas $v_{1}$ is only Raman active, in the free molecule; however, when a carbon dioxide molecule interacts with a surface it is no longer a free molecule and its symmetry is lowered; as a result, the $v_{1}$ mode becomes infrared active, and a band is observed [27].

In our spectrum the asymmetric stretching vibration of carbon dioxide molecule was observed at $2346 \mathrm{~cm}^{-1}$, that is, it is red-shifted in comparison to the value of $2349 \mathrm{~cm}^{-1}$ reported for gas-phase $\mathrm{CO}_{2}$; given that, the observed band is the result of the attachment of the carbon dioxide molecule by dispersive and electrostatic forces to the adsorption space defined by the PBA framework [11]; i.e., adsorption produces the confinement of the carbon dioxide molecule and thereafter the frequency shift [31]. Subsequently, this band corresponds to physically adsorbed carbon dioxide molecules $[5,30]$; i.e., a state equivalent to those of loosely bound or non-coordinated water in the PBA framework, namely, the adsorbed carbon dioxide must be located in the interstitials sites of the Zn-HII framework [24]. Besides, the smaller band at about $2332 \mathrm{~cm}^{-1}$ is normally assigned to a combination band [29].

Another band corresponding to the adsorption of carbon dioxide on electron accepting Lewis acid sites which is normally found at higher frequencies [29] was not observed in our spectrum (Fig. 4); since these sites are occupied by coordinated water [6]; which is released at a temperature higher $(423 \mathrm{~K})$ than those used here to activate the $\mathrm{Zn}$-HII sample namely $373 \mathrm{~K}$ (see Fig. 3b); accordingly, are not suitable for carbon dioxide adsorption. 
Thereafter, the DRIFTS data allowed us to conclude that the $\mathrm{CO}_{2}$ adsorbed molecules must be located in the interstitial sites near to the $\mathrm{K}^{+}$cation and the cavity wall, since the kinetic diameter of the $\mathrm{CO}_{2}$ molecule, an ellipsoidal molecule, $5.4 \AA$ long with a diameter of $3.4 \AA$ approximately fit these sites. Hence, within this site the strong interaction between the electric potential of the cation with the quadrupolar moment of the carbon dioxide molecule is responsible for the relatively strong interaction [11].

Next, to measure the adsorption isotherms, the excess adsorption amount was measured with the volumetric method using the following equation: $n_{e}=n_{a}-\rho_{g} V_{g}$, in which, $n_{a}$, was the total amount adsorbed, $\rho_{g}$, the adsorbate density and $V_{g}$, the dead volume [32] that include the pore volume of the adsorbent, specifically, to measure, $V_{g}$, was used a reference gas, specifically, He, for which the amount adsorbed, $n_{a}$, is considered zero i.e., $n_{a}=n_{e}+\rho_{g} V_{g}=0$, accordingly, $V_{g}=n_{t} / \rho_{g}$, where, $\rho_{g}$, is the density of He [33]. Thereafter, to characterize the adsorption space of the tested $\mathrm{Zn}-\mathrm{HII}$, the collected adsorption data at $273 \mathrm{~K}$ and $300 \mathrm{~K}$ in the low pressure range (up to 1 Bar) was fitted to the Dubinin-Radushkevitch (D-R) adsorption isotherm equation (Fig. b) [34]:

$$
\ln \left(n_{a}\right)=\ln \left(N_{a}^{0}\right)-\left(\frac{R T}{E}\right)^{2} \ln \left(\frac{P_{0}}{P}\right)^{2}
$$

Wherein, $n_{a}$, is the amount adsorbed, where, $P$, is the adsorption equilibrium pressure and, $P_{0}$, is the vapor pressure of carbon dioxide, $E$, is the characteristic energy of adsorption, and, $N_{a}^{0}$, is the maximum amount adsorbed in the micropore volume. In Table 2 are reported the parameters calculated in the course of the fitting process, specifically: $E, N_{a}^{0}$ and $W_{0}$, the micropore volume, 
calculated using the Gurtvich rule, i.e., $W_{0}=N_{a}^{0} V_{\mathrm{CO}_{2}}$, where, $V_{\mathrm{CO}_{2}}=48.3 \mathrm{~cm}^{3} / \mathrm{mol}$. The measured pore volume indicated that was produced a material with a developed porosity in the micropore range. In addition, the computed characteristic energy of adsorption, $E$, is particularly high; consequently, the mutual interaction between the carbon dioxide molecule and the $\mathrm{Zn}-\mathrm{HII}$ PBA framework must be noteworthy [35].

Now, in Fig. 5a are exhibited the high pressure carbon dioxide adsorption isotherms at $263 \mathrm{~K}$, $273 \mathrm{~K}, 300 \mathrm{~K}$ and $318 \mathrm{~K}$ in terms of the absolute carbon dioxide adsorption magnitude of $n_{a}$ (mmol $/ g)$. Afterwards, in Fig. $5 \mathrm{~b}$ are reported the plots of the pore volume versus de adsorption equilibrium pressure, $\mathrm{P}$, using the adsorption data reported in Fig. 5a. To further characterize the adsorption space of the tested Zn-HII, the collected high pressure adsorption data was fitted to equation "1" i.e., the Dubinin-Radushkevitch (D-R) adsorption isotherm equation [34]. In Table 3 are reported the parameters computed during the fitting process, to be precise, $E, N_{a}^{0}$ and $W_{0}$. The obtained data, notwithstanding the fact that was obtained using a different pressure range (Table 2) produced comparable results, i.e., a material showing developed microporosity and a high characteristic energy of adsorption, $E$.

Moreover, to more precisely quantify the adsorbate-adsorbent interaction, the isosteric heat of adsorption, $q_{i s o}$, was calculated using a relation similar to the Clausius-Clapeyron equation, as follows [36]:

$$
q_{\text {iso }} \approx R T^{2}\left\lfloor\frac{d \ln P}{d T}\right\rfloor_{n_{a}} \approx R T_{1} T_{2}\left\lfloor\frac{\ln P_{2}-\ln P_{1}}{T_{2}-T_{1}}\right\rfloor_{n_{a}}
$$

Where, $P_{1}$ and $P_{2}$ are the equilibrium adsorbate pressure at, $n_{a}=$ constant, for the temperatures $T_{1}$ and $T_{2}$. The results of the calculations were plotted in Fig. 5c, in which, $\theta=n_{a} / N_{a}$. The obtained data indicated that the adsorption process in the $\mathrm{Zn}-\mathrm{HII}$ was energetically 
heterogeneous [37]. This effect occurs because the adsorption process at low coverage is dominated by the adsorbate-adsorbent interactions and at higher coverage by the adsorbateadsorbate interactions [38]. Specifically, when a molecule contact the surface of a solid adsorbent, it become subjected to: the dispersion energy, $\phi_{D}$, repulsion energy, $\phi_{R}$, polarization energy, $\phi_{P}$, field dipole energy, $\phi_{E \mu}$, field gradient quadrupole energy, $\phi_{E Q}$, and as well some specific acid-base interactions, $\phi_{A B}$, together with the adsorbate-adsorbate interaction energy, $\phi_{A A}$ [39]. In the case of a molecule like carbon dioxide, that shows a noticeable quadrupolar moment this fact give raise to specific interactions, where the combination of the dispersive and electrostatic attractive interactions are normally relatively strong $[40,41]$.

These data also indicated that as a consequence of the adsorption process the micropore volume was not saturated, conversely, it continuously increased with the adsorption equilibrium pressure. This fact is possible because an adsorbent in the course of the adsorption processes could experience deformation [13], that is, adsorption can produce the expansion of the adsorbent structure [14,15]. In Fig. 6b is observed an uninterrupted framework expansion process.

Now, to work out the adsorption process an important assumption was made, specifically, the adsorbent plus the adsorbed phase was considered as a solid solution, i.e., the adsorbateadsorbent system $(a A)$; thereafter, the fundamental thermodynamic equation, within the frame of the solution thermodynamic approach; for this system is given by [43]:

$$
d U_{a A}=T d S_{a A}-P d V_{a A}+\mu_{a} d n^{a}+\mu_{A} d m
$$

Where, $U_{a A}, S_{a A}$ and $V_{a A}$ are the internal energy, entropy and volume of the system $a A$, while $\mu_{a}$ ( in $J / \mathrm{mol}$ ) and $\mu_{A}$ (in $J / K g$ ) are the chemical potentials of the adsorbed and solid phases in the solution and, $n^{a}$, and $m$ the amount of moles of adsorbate and the adsorbent mass in the system $a A$. Hence: 


$$
U_{a A}=T S_{a A}-P V_{a A}+\mu_{a} n^{a}+\mu_{A} m
$$

On this ground, is possible to write the internal energy per unit mass of adsorbent as follows:

$$
\bar{U}_{a A}=T \bar{S}_{a A}-P \bar{V}_{a A}+\mu_{a} n_{a}+\mu_{A}
$$

Where, $n_{a}=n^{a} / m$. Now the internal energy for the unit mass of empty adsorbent is given by:

$$
\bar{U}_{A}=T \bar{S}_{A}-P \bar{V}_{A}+\mu_{A}^{0}
$$

Therefore:

$$
U_{a}=\bar{U}_{a A}-\bar{U}_{A}=T S_{a}-P V_{a}+\mu_{a} n_{a}+\Phi
$$

Where, $S_{a}=\bar{S}_{a A}-\bar{S}_{A} \quad, \quad V_{a}=\bar{V}_{a A}-\bar{V}_{A} \quad$ and $\quad \Phi=\mu_{A}-\mu_{A}^{0}$. Likewise, the fundamental thermodynamic equation for the adsorbed phase is given by:

$$
d U_{a}=T d S_{a}-P d V_{a}+\mu_{a} d n_{a}+d \Phi
$$

Therefore, since the Grand potential is defined as: $\Omega=U-T S-\mu n$, hence:

$$
\begin{gathered}
\Omega_{a}=U_{a}-T S_{a}-\mu_{a} n_{a}-\Phi \\
d \Omega_{a}=d U_{a}-T d S_{a}-S_{a} d T-d \mu_{a} n_{a}-\mu_{a} d n-d \Phi
\end{gathered}
$$

Consequently, substituting equation " 5 " in equation "6" we get:

$$
d \Omega_{a}=-P d V_{a}-S_{a} d T-n_{a} d \mu_{a}
$$

Now, in equilibrium: $d \mu_{a}=d \mu_{g}=R T \ln f$, where $f$, is the fugacity of the adsorbate, thereafter:

$$
d \Omega_{a}=-P d V_{a}-S_{a} d T-n_{a} R T \ln f=d \Phi
$$

But since $\Omega_{a}=\Phi[34]$, then, for $T=$ const:

$$
\Phi=R T \int_{0}^{f} n_{a} d(\ln f)-V_{a} P
$$

In the frame of the osmotic theory of adsorption [44], $\Phi=\Pi W$, hence: 


$$
\Pi W=R T \int_{0}^{f} n_{a} d(\ln f)-V_{a} P
$$

Where, $W$, is the micropore volume of the adsorbent and, $\Pi=P^{0}-P$, is the osmotic pressure where $P^{0}$, is a pressure that can compress the adsorbate and produce the same effect created by an adsorption field, i.e., $n_{a}$, adsorbed molecules [22]. Since we are working at not very high pressure hence, $f \approx P$ and $V_{a} P \approx 0$, thereafter:

$$
\Pi \approx \frac{R T}{W} \int_{0}^{f} n_{a} d(\ln P)
$$

Accordingly, in Fig. 6 a is shown the $\Pi$ versus $P$ plot, calculated using equation "10". This figure shows a maximum in the osmotic pressure versus pressure plot, fact indicating that a pressureresponsive framework opening sorption event, took place due to a structural transformation in the adsorbent framework induced by the guest molecules [46,47]. After this effect, the micropore volume shows a steady increase with the increment of the equilibrium adsorption pressure (Fig. $6 b)$; that is, the framework of the tested materials experienced a framework expansion event induced by the guest molecule. Hence, the amount adsorbed increase with the equilibrium adsorption pressure an effect that could be very useful if this material is applied in gas storage.

\section{Conclusions}

Notwithstanding the fact that during the last years hexacyanoferrates have been extensively studied; the high pressure adsorption properties of Zn (II) hexacyanoferrate (II) has not been considered. Hence the synthesis and structural characterization, together with their low (up to 1 Bar) and high pressure (up to 30 Bar) adsorption properties, to discover if these materials show the structural flexibility effect of the Prussian blue analogue labelled Zn-HII were investigated in 
the reported research. To achieve the anticipated objectives, the structural characterizations using, X-ray diffraction, scanning electron microscopy, energy dispersive X-ray analysis, diffuse reflectance infrared Fourier transform spectrometry and thermo-gravimetric analysis was made. Concurrently, the adsorption thermodynamics of carbon dioxide was investigated. As a result of these studies we concluded that the Zn-HII displayed a structure characterized by the $F m \overline{3} m$ space group framework. Besides, the carbon dioxide adsorption investigation demonstrated the

presence of the framework expansion effect together with an extremely high adsorption heat, properties that could be useful for the use of $\mathrm{Zn}$ (II) hexacyanoferrate(II) as an excellent adsorbent.

\section{Acknowledgments.}

The authors acknowledges the financial support provided by the US DoE through the Massey Chair project and recognize the support of the NSF under the project CHE-0959334. We, as well, recognize Dr. C. Lozano for his assistance in the synthesis and structure elucidation of the tested material.

\section{References}

[1] Roque-Malherbe, R.; Lozano, C.; Polanco, R.; Marquez, F.; Lugo, F.; HernandezMaldonado, A.; Primera-Pedrozo, J.N. J. Sol. State Chem. 2011, 184, 1236

[2] Balmaseda, J.; Reguera, E.; Gomez, A.; Roque, J.; Vazquez, C.; M. Autie, M. J. Phys. Chem. B 2003, 107, 11360. 
[3] Roque-Malherbe, R. Physical Chemistry of Materials. Energy and Environmental Applications, CRC Press-Taylor \& Francis, Boca Raton, FL, USA, 2009.

[4] Verdaguer, M. Girolami, G. Magnetism: Molecules to Materials V. Edited by Miller, J. S.; Drillon, M.; WILEY-VCH Verlag GmbH \& Co. KGaA, Weinheim, 2004 ISBN : 3-527-30665-X [5] Natesakhawat, S.; Culp, J.T.; Matranga, C.; Bockrath, B. J. Phys. Chem. C, 2007, 111, 1055

[6] Jimenez-Gallegos, J.; Rodriguez-Hernandez, J.; Yee-Madeira, H.; Reguera, E. J. Phys. Chem. C 2010, 114, 5043

[7] Okubo, M.; Asakura, D.; Mizuno, Y.; Kim, J.-D.; Mizokawa, T.; Kudo, T.; Honma, I. J. Phys. Chem. Lett. 2010, 1, 2063

[8] Avila, M.; Rodrıguez-Hernandez, J; Lemus-Santana, A. ; Reguera, E. Journal of Physics and Chemistry of Solids (2011), 72, 988.

[9] Ludi, A.; Güdel, H.U. Struct. Bonding (Berlin) 1973, 14, 1-21

[10] Loos-Neskovic, C.; Ayrault, S.; Badillo, V.; Jimenez, B.; Garnier, E.; Fedoroff, M.; Jones, D.J.; Merinov, B. J. Solid State Chem. 2004, 177, 1817.

[11] Roque-Malherbe, R. Adsorption and Diffusion of Gases in Nanoporous Materials, CRC Press-Taylor \& Francis, Boca Raton, FL, USA, 2007.

[12] de Taconi, N.R.; Rajeshwar, K.; Lezna, R.O. Chem. Mater. 2003, 15, 3046

[13] Tvardoskiy VA. Sorbent deformation. The Netherland: Elsevier; 2006.

[14] Coudert, F-X. Phys. Chem. Chem. Phys., 2010, 12, 10904

[15] Maji, T. K.; Kitagawa, S. Pure and Applied Chemistry 2007, 79, 2155.

[16] Buckingham, A.D. Proc. Royal Soc. Series A. 1963, 273, 275.

[17] Bhatt, P.; Thakur, N.; Mukadam, M.D.; Meene, S.S.; Yusuf, S.M., J. Phys. Chem. C. 2013, 117,2676 
[18] Martinez-Garcia, R.; Reguera, E.; Rodriguez, J.; Balmaseda, Roque, J. Powder Diffraction 2004, 19, 284-291.

[19] C. Loos-Neskovic, M. Fedoroff Reactive Polymers, Ion exchangers, Sorbents 1988, 7, $173-$ 183

[20] M. Avila, L. Reguera, J. Rodrıguez-Hernandez, J. Balmaseda, E. Reguera J. Solid State Chem. 2008, 181, 2899-2907

[21] F. Adekola, M. Fedoroff, S. Ayrault, C. Loos-Neskovic, E. Garnier, and L.-T. Yu, J. Solid State Chem. 1996, 132, 399-406

[22] Adak, S.; Daemen, L.L.; Hartl, M.; Williams, D.; Summerhill, J.; Nakotte, H. J. Solid State Chem. 2011, 184, 2854

[23] Lehto, J. and Haukka, S. Thermochim. Acta 160 (1990) 343-347

[24] Hahn, T. (Ed.), International Tables for Crystallography (fifth edition), The International Union of Crystallography, Springer, Volume A, 2005.

[25] Sato, O.; Iyoda, T.; Fujishima, A.; Hashimoto, K., Science 1996, 272 , 704

[26] A. L. Goodman, L. M. Campus, and K. T. Schroeder Energy \& Fuels 2005, 19, 471-476

[27] B. Bonelli, B. Onida, B. Fubini, C. Otero Arean, and E. Garrone Langmuir 2000, 16, 49764983

[28] Llabres i Xamena, F.X.; Zecchina, A. Phys. Chem. Chem. Phys. 2002, 4, 1978

[29] Knozinger, H.; Huber, S. J. Chem. Soc., Faraday Trans., 1998, 94, 2047.

[30] Roque-Malherbe, R.; Polanco-Estrella, R.; Marquez-Linares, F. J. Phys. Chem. C. 2010, 114,17773

[31] Roque-Malherbe, R.; Uwakweh, O.N.C. ; Lozano, C.; Polanco, R.; Hernandez-Maldonado, A.; Fierro, P.; Lugo, F.; Primera-Pedrozo, J. N. J. Phys. Chem. C 2011, 115, 15555 
[32] Sing, K.S.W.; Everett, D.H.; Haul, R.A.W.; Moscou, L.; Pirotti, R.A.; Rouquerol, J.; Siemieniewska, T., Pure App. Chem., 1985, 57, 603

[33] Gumma, S.; Talu, O. Langmuir 2010, 26, 17013

[34] Bering, B.P.; Dubinin, M.M.; Serpinskii, V.V. J. Coll. Int. Sci. 1972, 38, 185.

[35] Roque-Malherbe, R. Mic. Mes. Mat. 2000, 41, 227.

[36] S. Ross and J.P. Olivier, On Physical Adsorption, J. Wiley \& Sons, New York, 1964.

[37] W. Rudzinski and D.H. Everett, Adsorption of Gases in Heterogeneous Surfa Academic Press, London, 1992.

[38] Dunne, J.A.; Rao, M.; Sircar, S.; Gorte, R.J.; Myers, A.L. Langmuir 1996, 12, 5896.

[39] Ruthven, D. M. Principles of Adsorption and Adsorption Processes; John Wiley and Sons: New York, 1984.

[40] Dubinin, M.M. Rathmatkariev, G.U. and Isirikyan, A.A., Izv. Akad. Nauk. SSSR, Ser. Khim. 1989, 11, 2636-2638.

[41] Barrer, R.M. and Gibbon, R. Trans. Far. Soc. 1965, 61, 948-961.

[42] Omi, H.; Ueda, T.; Miyakubo, K.; Eguchi, T. App. Surf. Sci. 2005, 252, 660

[43] Myers, A.L.; Monson, P.A. Langmuir 2002, 18, 10261

[44] Bering, V.P. ; Serpinskii, V.V. Izv. Akad. Nauk SSSR, ser. xim. 1974, 2427.

[45] Lide, D.R. (editor in chief) Handbook of Chemistry and Physics ( $83^{\text {rd }}$ edition), CRC Press, Boca Raton, 2002, 6-46

[46] Neimark, A.V.; Coudert, F.X.; Triguero, C.; Boutin, A.; Fuchs, A.H. Langmuir 2011, 27, 4734.

[47] Walton, K.S.; Millward, A.R.; Dubbeldam, D.; Frost, H.; Low, J.J.; Yaghi, O.M.; Snurr, R.Q. J. Am. Chem. Soc. 2008, 130, 406. 


\section{Captions to the figures}

Fig.1. X-Ray diffraction profile refined using the Pawley method (a) and Scanning Electron Micrograph (b) of the tested material

Fig.2. Diffuse Reflectance Infrared spectra of the Hydrated and De-Hidydrated Zn-PBA-I materials in the $1500-2500 \mathrm{~cm}^{-1}$ (a) and $2500-4000 \mathrm{~cm}^{-1}$ (b) ranges

Fig.3. Generated with the PowderCell software framework and XRD profile of the Zn-PBA-I material

Fig.4. Diffuse Reflectance Infrared spectra of $\mathrm{CO}_{2}$ adsorbed, in Zn-PBA-I CO $\mathrm{CO}_{2}$ (a) along with the D-R-plots of the adsorption isotherms at $273 \mathrm{~K}$ and $300 \mathrm{~K}$.

Fig.5. Plots of the $\mathrm{CO}_{2}$ adsorption isotherms at 263, 273, 300 and 315-K (a) and the isosteric heat of adsorption (b)

Fig.6. Plot of the parameter $\Pi$ versus the adsorption pressure P. 


\section{Counts Figure 1}
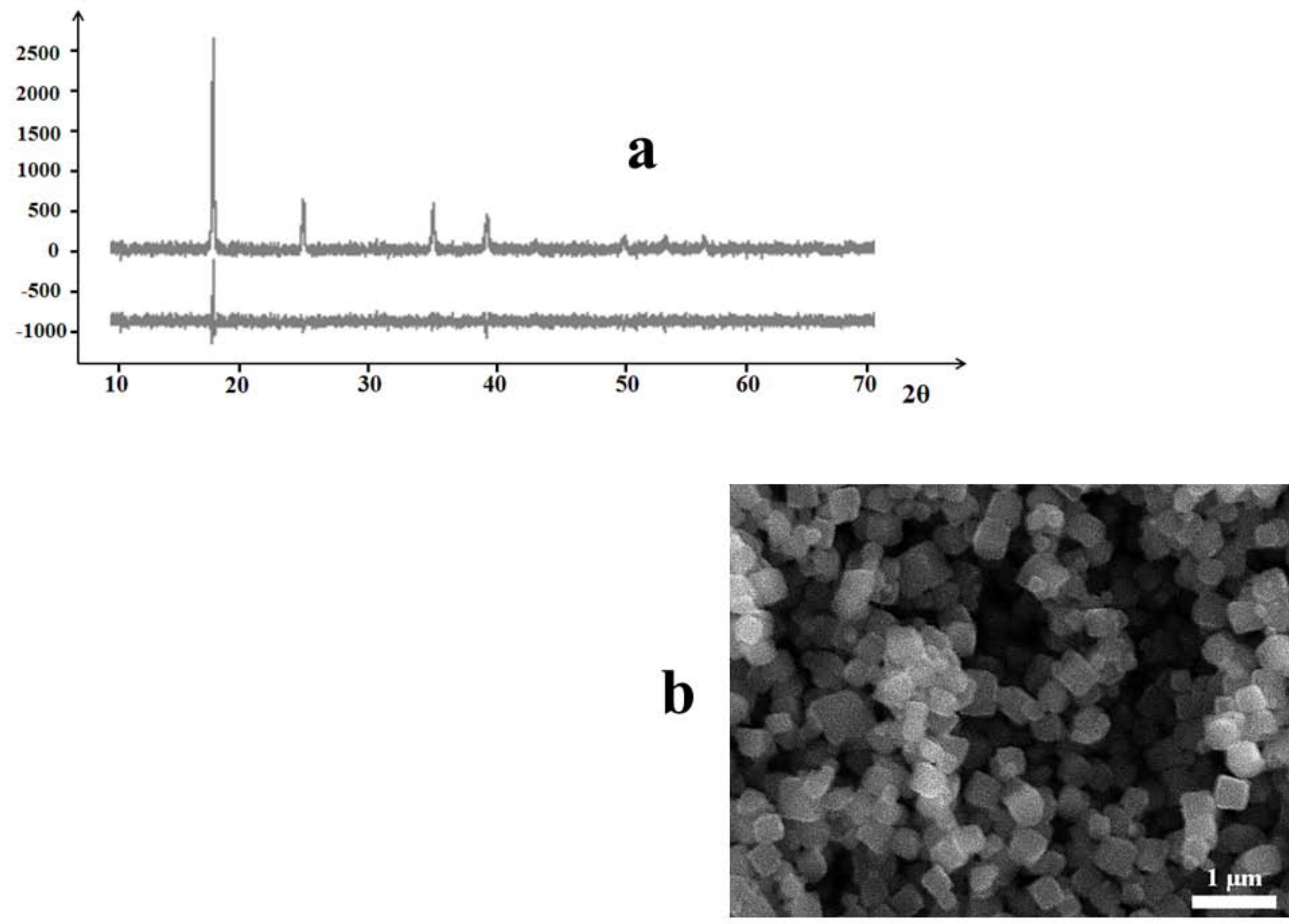


\section{Figure 2}
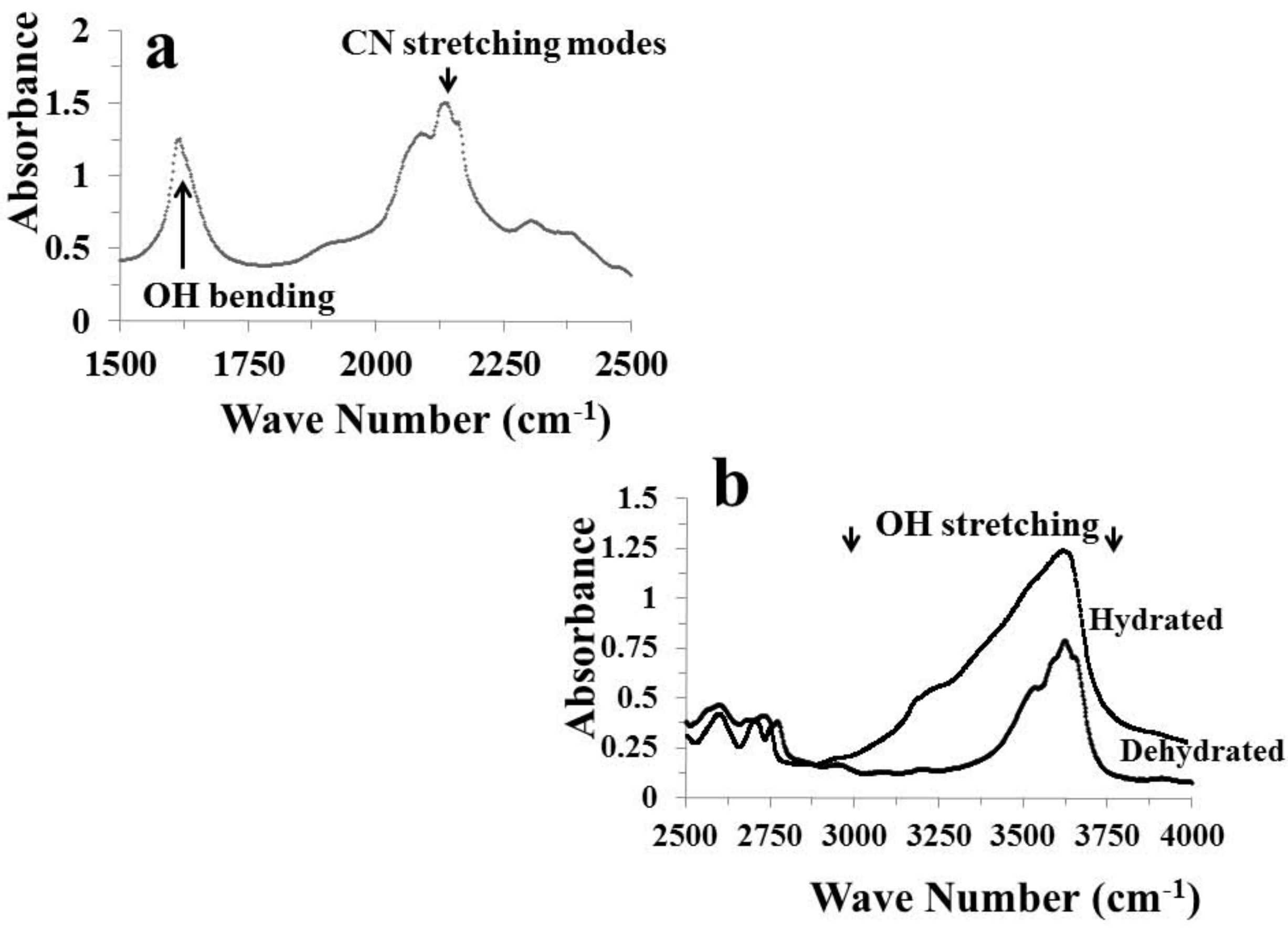


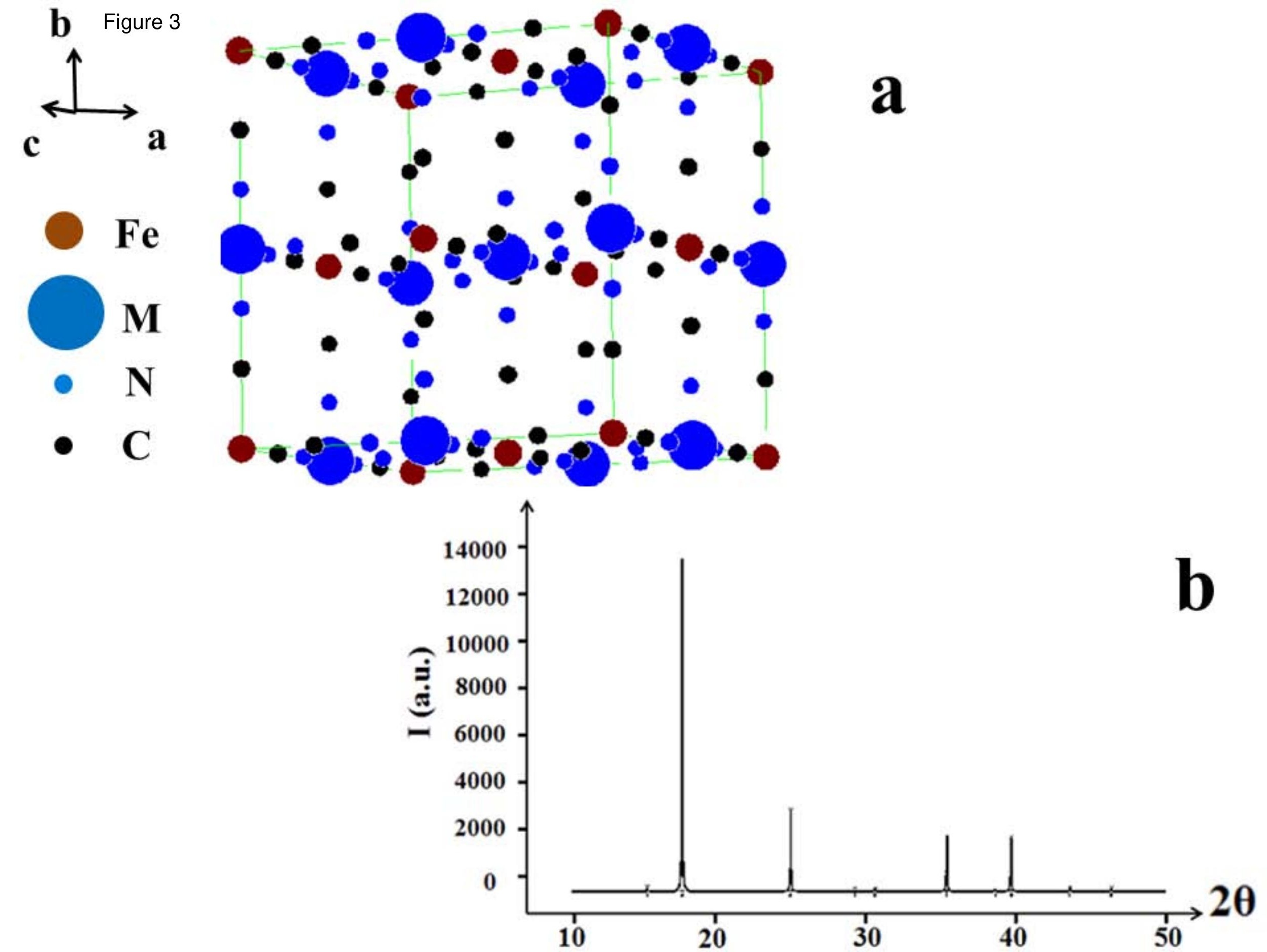


Absorbance

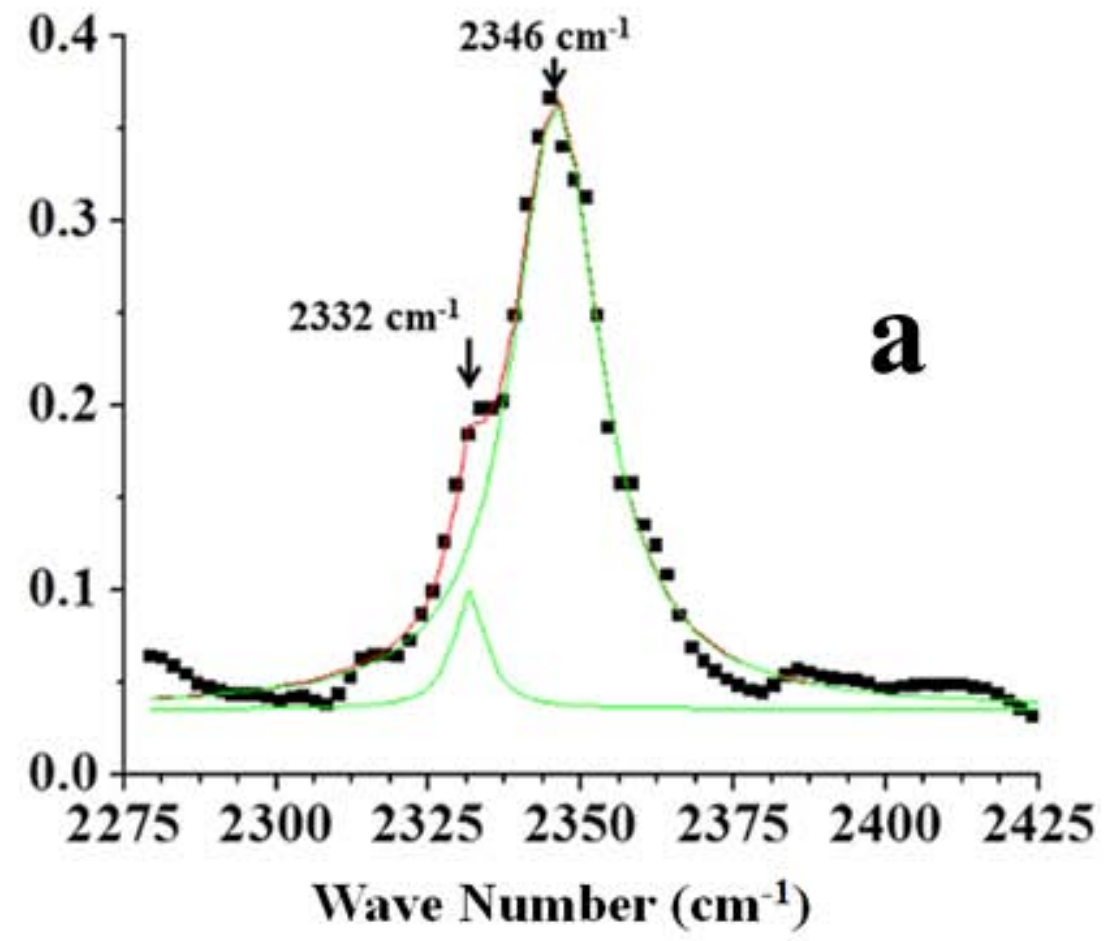

$\ln \left(n_{a}\right)$
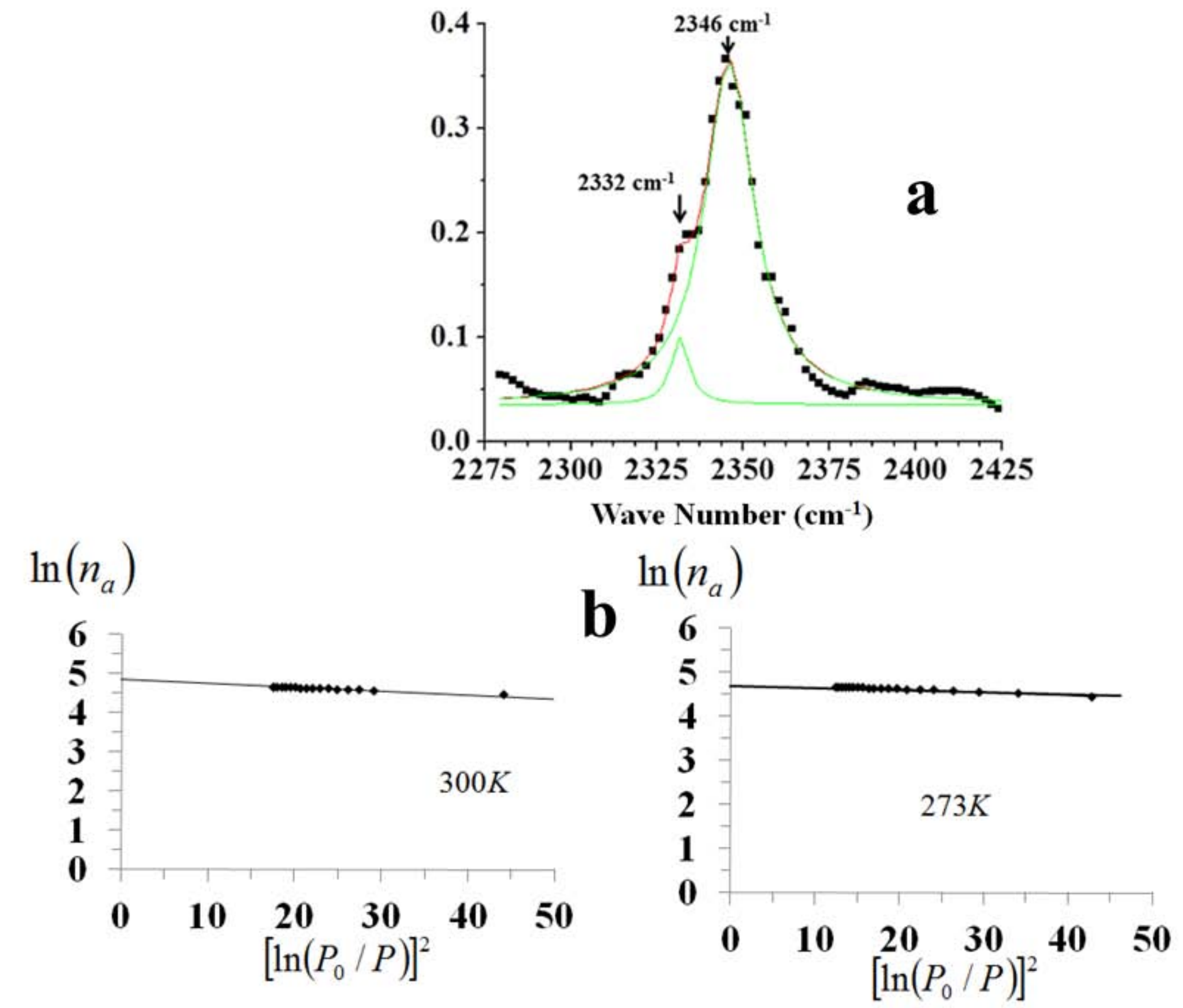

\section{Figure}


$n_{t}[\mathrm{mmol} / \mathrm{g}]$ Figure 5

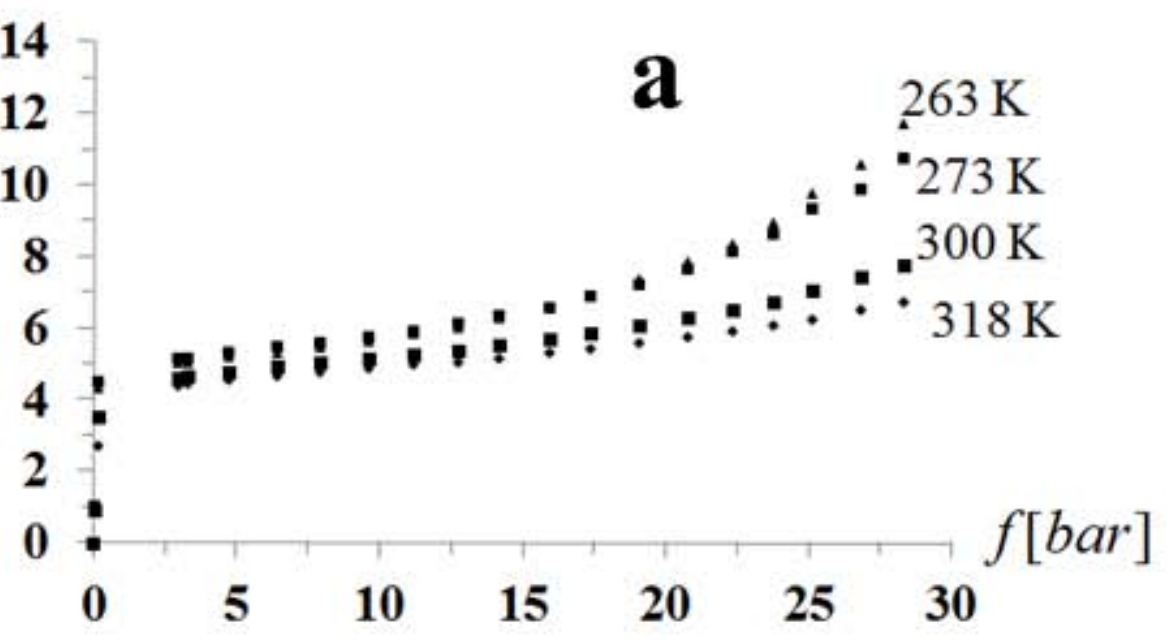

$W\left[\mathrm{~cm}_{0.7}^{3} / \mathrm{g}\right]$

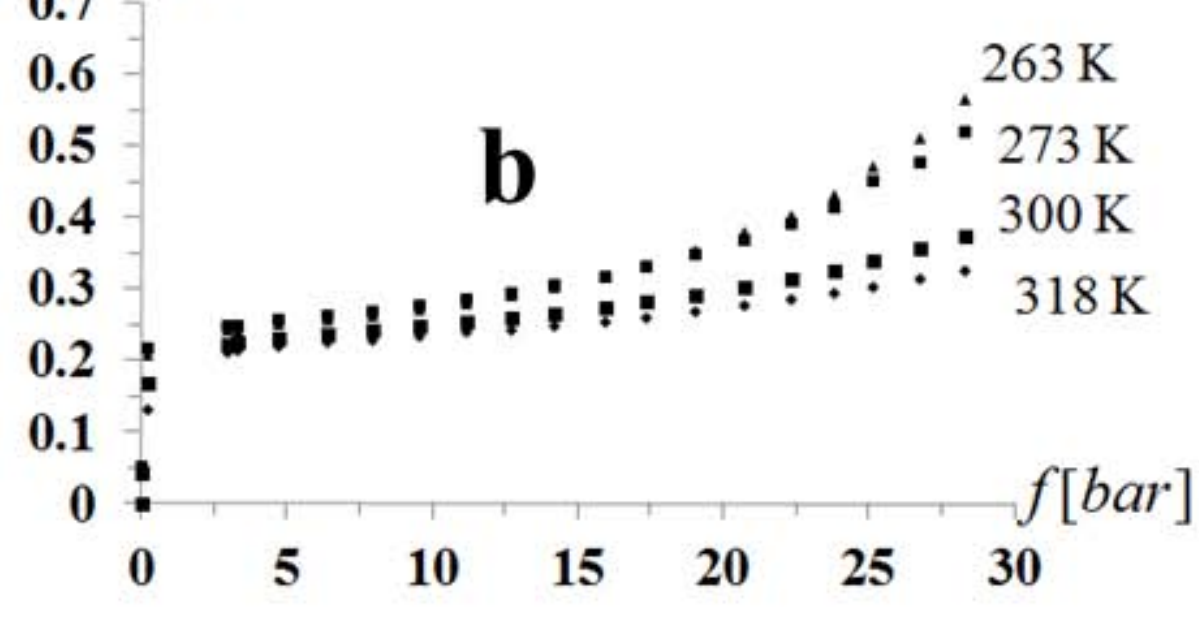

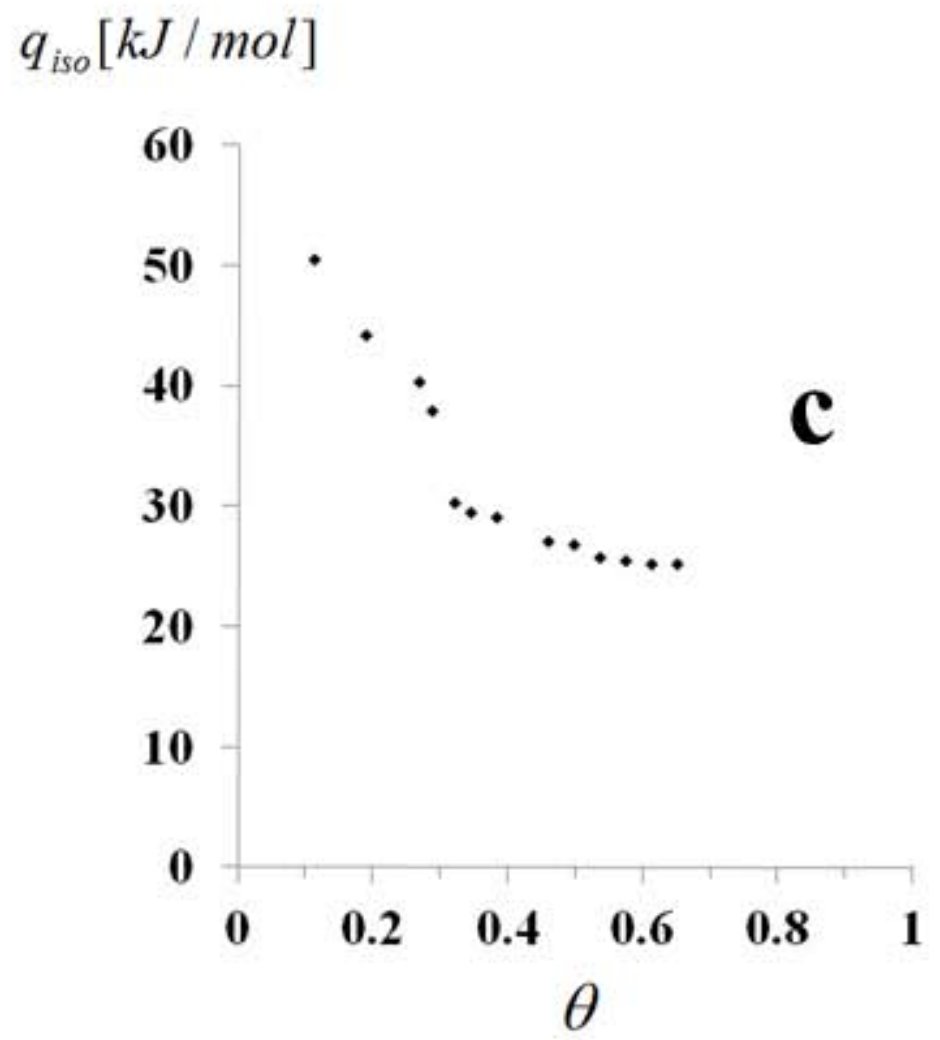




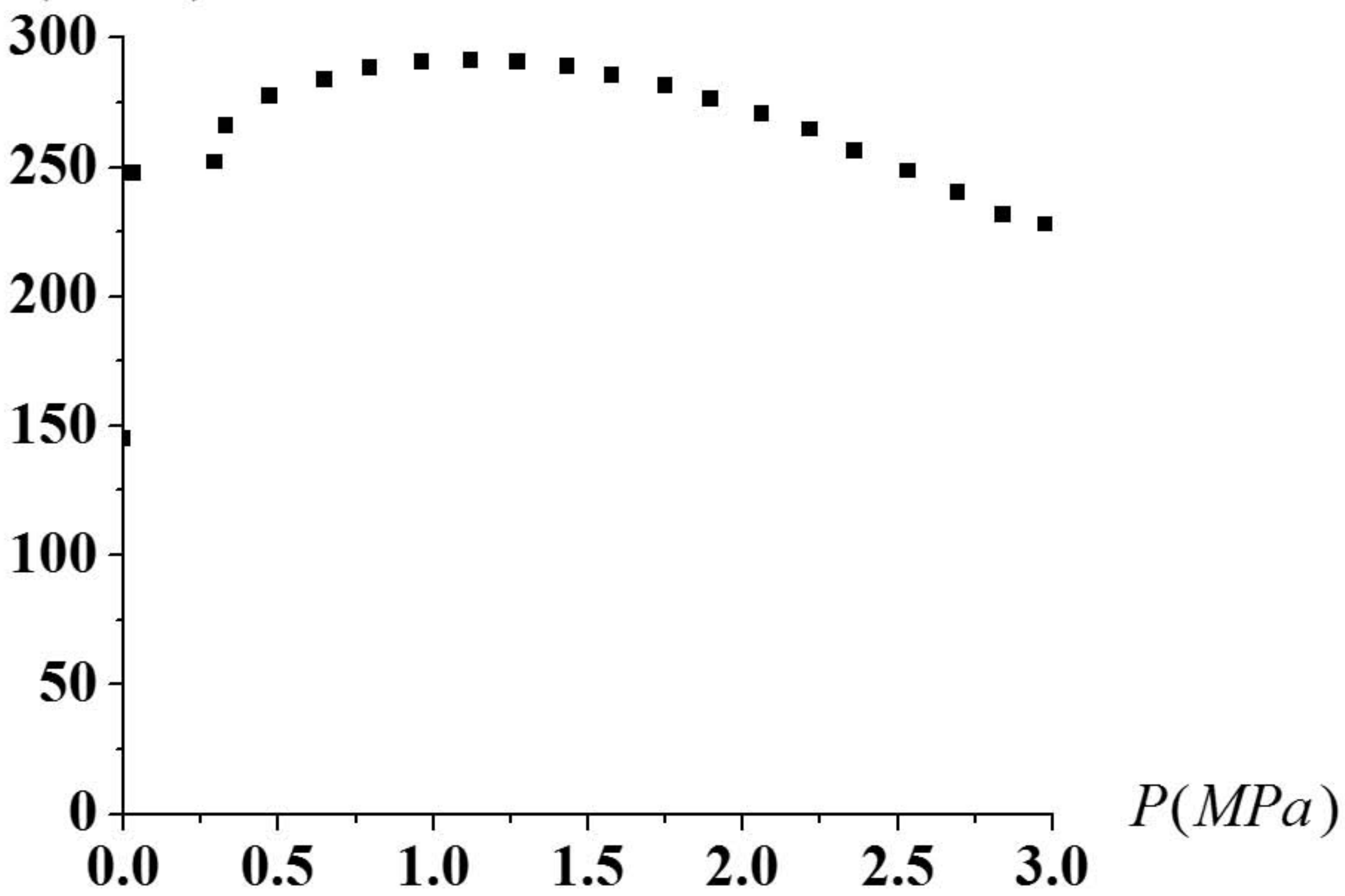




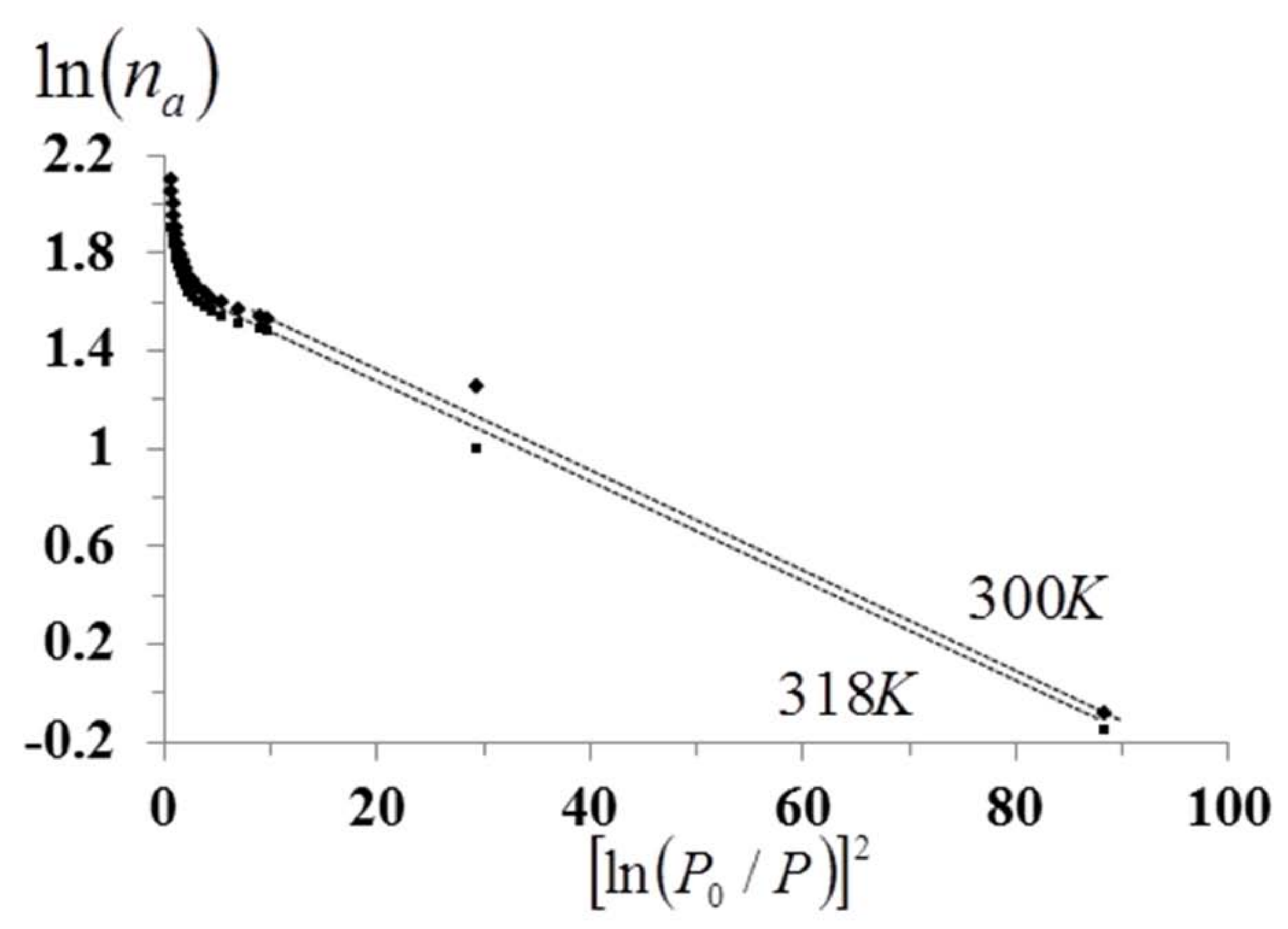


Table 1. Crystallographic information of the tested: Zn(II) hexacyanoferrate(II) (ZnHII).

\begin{tabular}{|l|l|l|l|}
\hline Sample & $\boldsymbol{a}(\bar{A})$ & $\boldsymbol{V}\left(\bar{A}^{3}\right)$ & S.G. \\
\hline Zn-HII & $10.231(3)$ & $1071(1)$ & $F m \overline{3} m$ \\
\hline
\end{tabular}


Table 2. Maximum amount adsorbed $\left(N_{a}\right)$ micropore volume $\left(W_{0}\right)$ and characteristic energy of adsorption calculated with the Dubinin-Radushkevitch equation for the adsorption of carbon dioxide at $273 \mathrm{~K}$ and $300 \mathrm{~K}$ up to 1 bar.

\begin{tabular}{|l|l|l|l|l|}
\hline Sample & $T[K]$ & $N_{a}^{0}(\mathrm{mmol} / \mathrm{g})$ & $E(\mathrm{~kJ} / \mathrm{mol})$ & $W_{0}\left(\mathrm{~cm}^{3} / \mathrm{g}\right)$ \\
\hline Zn-HII & 273 & 4.75 & 69 & 0.230 \\
\hline Zn-HII & 300 & 5.19 & 57 & 0.249 \\
\hline
\end{tabular}


Table 3. Maximum amount adsorbed $\left(N_{a}\right)$ micropore volume $\left(W_{0}\right)$ and characteristic energy of adsorption calculated with the Dubinin-Radushkevitch equation for the adsorption of carbon dioxide at $300 \mathrm{~K}$ and $318 \mathrm{~K}$ up to $10 \mathrm{bar}$.

\begin{tabular}{|l|l|l|l|l|}
\hline Sample & $T[\mathrm{~K}]$ & $N_{a}^{0}(\mathrm{mmol} / \mathrm{g})$ & $E(\mathrm{~kJ} / \mathrm{mol})$ & $W_{0}\left(\mathrm{~cm}^{3} / \mathrm{g}\right)$ \\
\hline Zn-HII & 300 & 4.75 & 47 & 0.228 \\
\hline Zn-HII & 318 & 5.55 & 45 & 0.266 \\
\hline
\end{tabular}

